\title{
Regional Variation in Amelanchier in the Whitewood area of Southeastern Saskatchewan and the First Saskatchewan Records of Amelanchier sanguinea
}

\author{
Paul M. Catling and G. Mitrow
}

Agriculture and Agri-Food Canada, Environmental Health, Biodiversity, Saunders Building, Central Experimental Farm, Ottawa, Ontario K1A 0C6 Canada; e-mail: catlingp@agr.gc.ca

Catling, Paul M., and G. Mitrow. 2006. Regional variation in Amelanchier in the Whitewood area of southeastern Saskatchewan and the first Saskatchewan records of Amelanchier sanguinea. Canadian Field-Naturalist 120(4): 428-432.

Based on measurements and evaluation of 111 specimens from 51 localities in the Whitewood area of southeastern Saskatchewan, most Amelanchier alnifolia from the prairie parkland is represented by short, stoloniferous shrubs, less than $2 \mathrm{~m}$ tall with $5-100+$ stems. In the Moose Mountain area, A. alnifolia is represented by shrubs that are taller, sometimes to $7 \mathrm{~m}$, not stoloniferous and usually having fewer than five stems. Although many of these plants have the inflorescence characteristics of A. alnifolia, some are referable to the eastern A. sanguinea, not previously reported from southeastern Saskatchewan. Such plants appear to be confined to the wooded environment of Moose Mountain. Amelanchier alnifolia is not as clearly differentiated by habit or leaf tip characteristics as the literature suggests. Inflorescence characteristics, habit and actual genetic variation may be associated with biogeographic patterns, especially historically wooded islands within the prairie ecozone. These patterns are an important consideration in classification studies and in protecting and utilizing Amelanchier germplasm.

Key Words: Juneberry, Serviceberry, Shadbush, Saskatoon, Amelanchier alnifolia, A. sanguinea, status, biogeophaphic variation, hybrid, agamospermy, Moose Mountain, Saskatchewan.

At least three species of Amelanchier are known to occur in the prairie region of Canada. Amelanchier alnifolia (Nutt.) Nutt. is widespread, Amelanchier florida Lindl. is confined to ravines in the Cypress Hills (reported by some authors and not by others) and A. sanguinea (Pursh) DC. occurs in southeastern Manitoba (e.g. Boivin 1967; Looman 1979). Reports of A. sanguinea from the northern Great Plains (Stephenson 1973; McGregor et al. 1977) are based on A. humilis Wieg. (McGregor et al. 1986), whereas Boivin's (1967) report of $A$. sanguinea in southeastern Manitoba may be based on material of both $A$. sanguinea and $A$. $h u$ milis since he combined the latter with the former and both occur in the general region and in northern Minnesota (Nielsen 1939; Jones 1946).

In general, flowering material of $A$. sanguinea is distinguished from A. alnifolia by having flowering pedicels more than $15 \mathrm{~mm}$ long instead of less than $10 \mathrm{~mm}$ long (Boivin 1967; Cinq-Mars 1971; Gleason and Cronquist 1991) and petals 11-22 mm long instead of 6-10 mm long (e.g., Jones 1946). In addition, A. sanguinea is characterized as a tree with oblong, pointed leaves and A. alnifolia is generally characterized as a stoloniferous shrub with truncate or rounded leaves (e.g., Nielsen 1939; Jones 1946; Fernald 1950). Amelanchier humilis is distinguished from A. alnifolia by its acute or obtuse instead of truncate or broadly rounded leaves (Cinq-Mars 1971; McGregor et al. 1986). McGregor et al. (1986) have indicated that it is difficult to separate A. alnifolia and A. humilis in the northern Great Plains and they have suggested that some colonies "appear as hybrid swarms and the two could easily be considered as variants of one species." The concept of including A. humilis with A. alnifolia is not new since it was the basis for McKay's (1973, $1975,1976)$ transfer of Nielsen's A. humilis var. compacta to A. alnifolia (A. alnifolia var. compacta (Nielsen) McKay).

During a survey of Amelanchier in the Whitewood and Moose Mountain areas of southeastern Saskatchewan in early June 2005, it appeared that plants in the prairie-parkland region (ecodistricts 752, 756, 760, Agriculture and Agri-Food Canada 1995) differed from those on the elevated Moose Mountain plateau (ecodistrict 761) which was forested in presettlement times (Catling and Kostiuk 2006). This rolling plateau, almost $400 \mathrm{~km}^{2}$ in extent with numerous lakes and welldrained wooded slopes with aspen (Populus) and birch (Betula) forest, is $100-150 \mathrm{~m}$ above the surrounding plains.

The objective of the work reported here was to document the variation and to provide a context for the first report of Amelanchier sanguinea in Saskatchewan. This information is relevant to systematic studies of Amelanchier and is also of interest with regard to the protection of native Amelanchier germplasm. Although Saskatoon (Amelanchier alnifolia) is one of Canada's fastest growing native crops, its variation is not well understood and its domestication has yet to take advantage of the full range of variability available (Catling and Small 2003). 


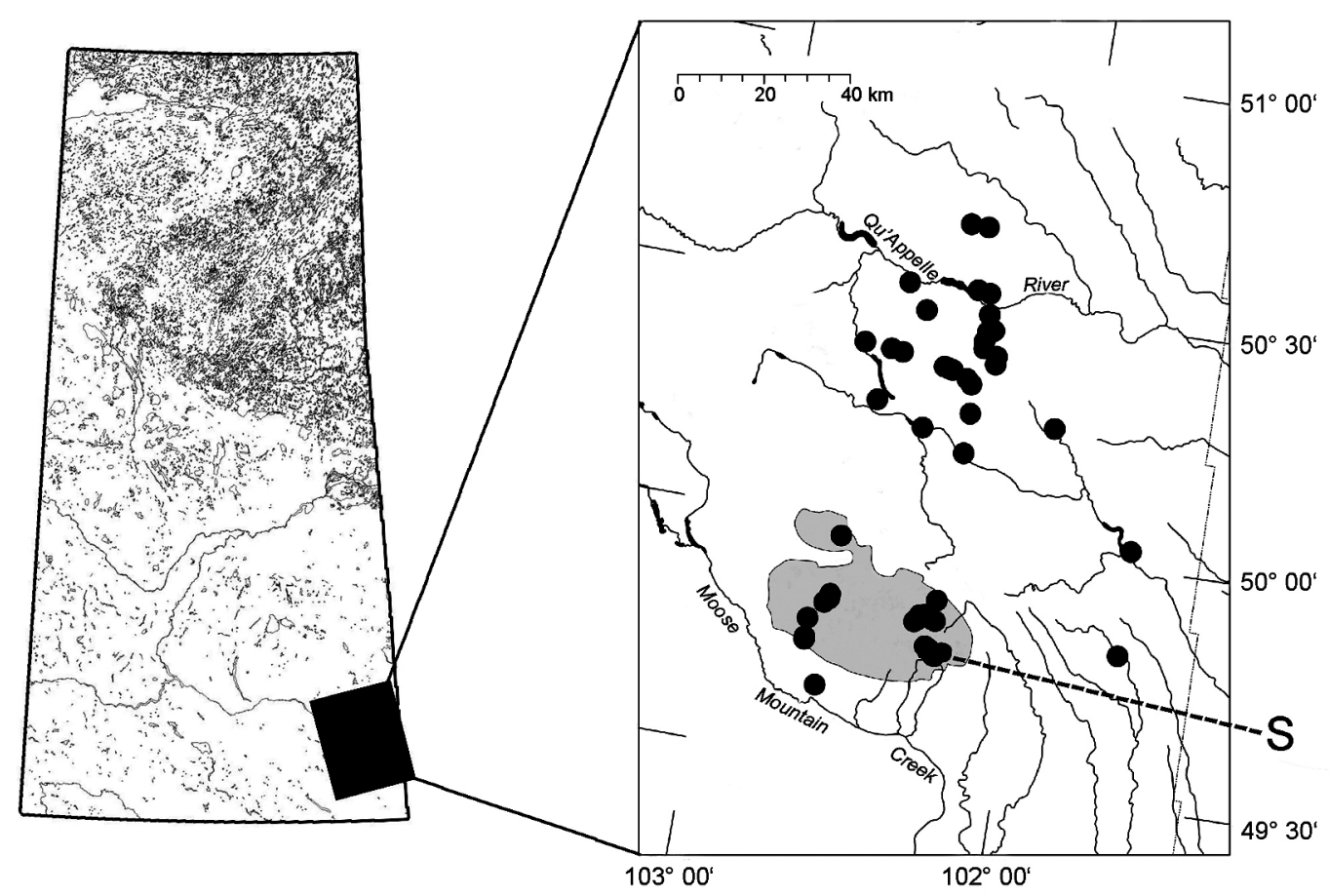

FIGURE 1. Saskatchewan (left) showing location of Whitewood study area (right). Collection localities of Amelanchier used in the study are indicated by dots. The Moose Mountain ecodistrict is shaded. The collection site of A. sanguinea is indicated by "S" and dashed line connected to the dot.

\section{Methods}

In June 2005, during late flowering, 111 specimens of Amelanchier were collected and measured from 51 sites in the Whitewood - Moose Mountain area of southeastern Saskatchewan (Figure 1). No more than five specimens were collected at each site and sites are defined as at least $0.1 \mathrm{~km}$ apart. Specimens were selected to represent the extremes of variation present at a site. For each specimen, lengths of lowest pedicel in an inflorescence of average size, average petal length in lowest flower in the inflorescence, average sepal length in lowest flower in the inflorescence, the plant habit (stoloniferous or not, height, number of stems), leaf pubescence (scale 1-4, 1 = glabrous, $4=$ densely pubescent) and shape of the tip of a larger leaf (scale 1-5 with $1=$ truncate, $5=$ pointed). Stoloniferous shrubs were defined as having more than 6 separated stems and being less than $2 \mathrm{~m}$ in height. Non-stoloniferous shrubs were defined as having 5 or fewer stems together and exceeding $2 \mathrm{~m}$ in height.

The data were analysed using Principal Components Analysis (PCA), regression and histograms. PCA reduced dimensionality of six characters (Table 1), to two allowing for an evaluation of grouping and indication of pattern of variation. Histograms evaluated pedicel length with respect to habitat for different ecodistricts. F-ratios based on the comparison of the mean square variance of the regression model to the mean square of the residual indicated relationship and sig- nificance of individual characters noted above. Statgraphics software (www. statgraphics.com) was used to perform all the statistical analyses.

\section{Results and Discussion}

On the PCA plot (Figure 2) that reduces the dimensionality of six characters, the first two components account for $32.53 \%$ and $25.75 \%$ of the sample variation and the third and fourth account for $16.90 \%$ and $11.68 \%$, respectively. On the first component, pedicel length, sepal length and height are heavily weighted whereas on the second component, leaf tip and leaf shape are heavily weighted. Leaf pubescence was not heavily weighted on either of the first two components. With a cumulative $58.28 \%$ of the sample variation accounted for in the diagram, the plot is marginally useful as an indication of potential groups, and groups are unclear. However, the plants from historically wooded Moose Mountain area occupy a specific part of the dispersion suggesting a different pattern of morphological variation from that represented elsewhere in the region.

The plants from Moose Mountain tend to have longer pedicels, and they are mostly non-stoloniferous (Figure 3). Variation in leaf tip shape, overall leaf shape, leaf pubescence and the inflorescence characters is extensive. Most plants on Moose Mountain that are presumably A. sanguinea on the basis of height and non-stoloniferous habit have to be treated as A. alni- 


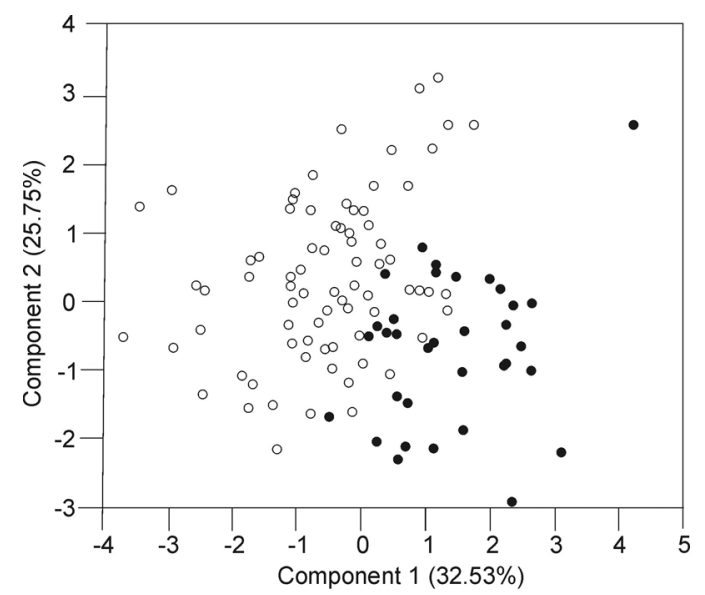

FIGURE 2. Plot of 111 specimens used in the study on the first two principal components derived from correllation among six morphological characters. The specimens from Moose Mountain are shown with solid dots and these occupy a specific portion of the dispersion suggesting distinctive variation within this region.

folia on the basis of pedicels less than $15 \mathrm{~mm}$ long and petals less than $10 \mathrm{~mm}$ long. The ten plants potentially referable to A. sanguinea on the basis of pedicels over $15 \mathrm{~mm}$ (Figure 3 ) had leaves with variable tips. For example five shrubs had more or less truncate leaves, four had most leaves broadly rounded and two had many pointed leaves. Leaf shapes also varied. Eight of these are moderately pubescent but two are more or less glabrous. All of these ten had petals over $9 \mathrm{~mm}$ but under $12 \mathrm{~mm}$ long. The two specimens accepted as A. sanguinea (e.g., Figure 4 left) had pedicels $17 \mathrm{~mm}$, petals $11-12 \mathrm{~mm}$, pointed, moderately pubescent, oblong leaves. These two plants were distinctive in blooming later than other plants nearby that possessed fewer A. sanguinea characteristics. The specimen label data for these are: SASKATCHEWAN: Moose Mountain: White Bear Lake, $49.7550^{\circ} \mathrm{N}, 102.2565^{\circ} \mathrm{W}$, 8 June 2005, P. M. Catling 05-27, B. Kostiuk (DAO); Good Bird Point, White Bear Lake, $49.7639^{\circ} \mathrm{N}$, 102.2328 ${ }^{\circ} \mathrm{W}, 6$ June 2005, P. M. Catling 05-16, B. Kostiuk (DAO). Amelanchier sanguinea has not been reported previously from Saskatchewan (Harms 2003).

Amelanchier alnifolia from the prairie parkland is represented mostly by short, stoloniferous shrubs, less than $2 \mathrm{~m}$ tall with 5-100+ stems, but taller, non-stoloniferous shrubs also occur in poplar groves. The smaller stoloniferous plants often have distinctively short and dense racemes with pedicels little if at all longer than the petals (Figure 4, right). The leaves may be truncate or more or less pointed.

The regressions indicated that pedicel length had the most significant relationships with other characteristics and was significantly correlated with ecodistrict (Table 1). Sepal length was also significantly correlat-

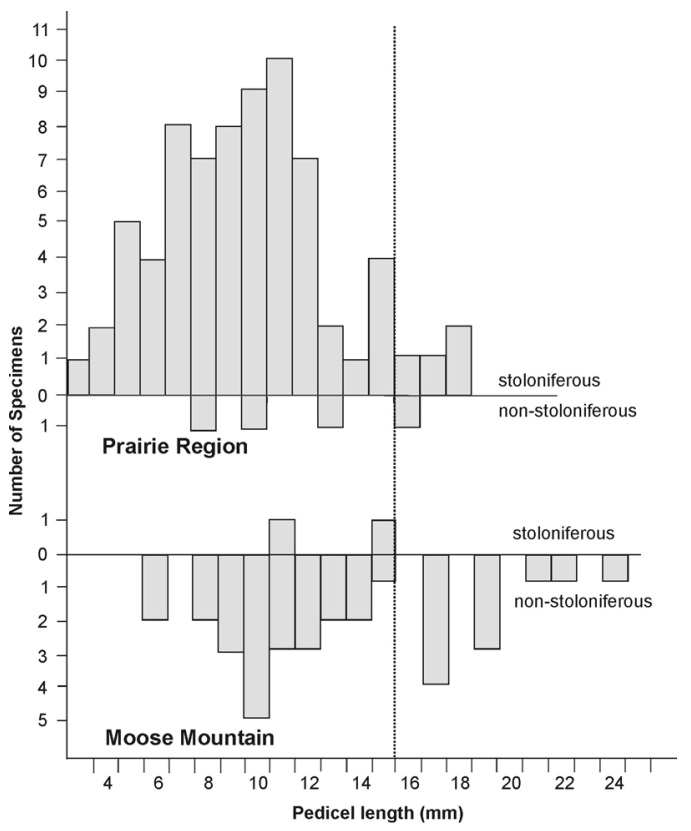

FIGURE 3. Histograms showing pedicel lengths and growth habits for specimens of Amelanchier from the prairie region and the Moose Mountain region of southeastern Saskatchewan.

ed with other characters, but was not significantly associated with leaf tip which is regarded as a significant character for distinguishing $A$. alnifolia by some authors (see above). In overall addition of significance values, pedicel length was three time more significant than sepal length. Futhermore, sepals are more often damaged or shrunken (as in fruit) whereas pedicels are more often intact. This represents the first quantitative support for the use of pedicel length in defining taxa. Leaf shape was only highly correlated with leaf tip and was not significantly related to ecodistrict suggesting limited use in defining taxa. These suggestions are based on the operational concept of taxa being defined by a number of correlated morphological characters and by some ecological discreteness. Thus the more recently defined (see above) characters are supported and these are included in the following key which will differentiate the four species known from the prairie provinces.

1a. Pedicels short, less than $10 \mathrm{~mm}$ long; petals

4-10 mm long; mostly stoloniferous shrubs ...... 2

2a. Leaves glabrous or sparsely tomentose at

flowering, truncate or broadly rounded ....A. alnifolia

2b. Leaves persistently pubescent at flowering,

obtuse to acute .................. humilis

1b. Pedicels longer, over $15 \mathrm{~mm}$ long; petals

11-22 mm long; non-stoloniferous shrubs . . . . . . 3

3a. Leaves glabrous at flowering $\ldots \ldots \ldots \ldots$. florida

3b. Leaves more or less tomentose at flowering A. sanguinea 


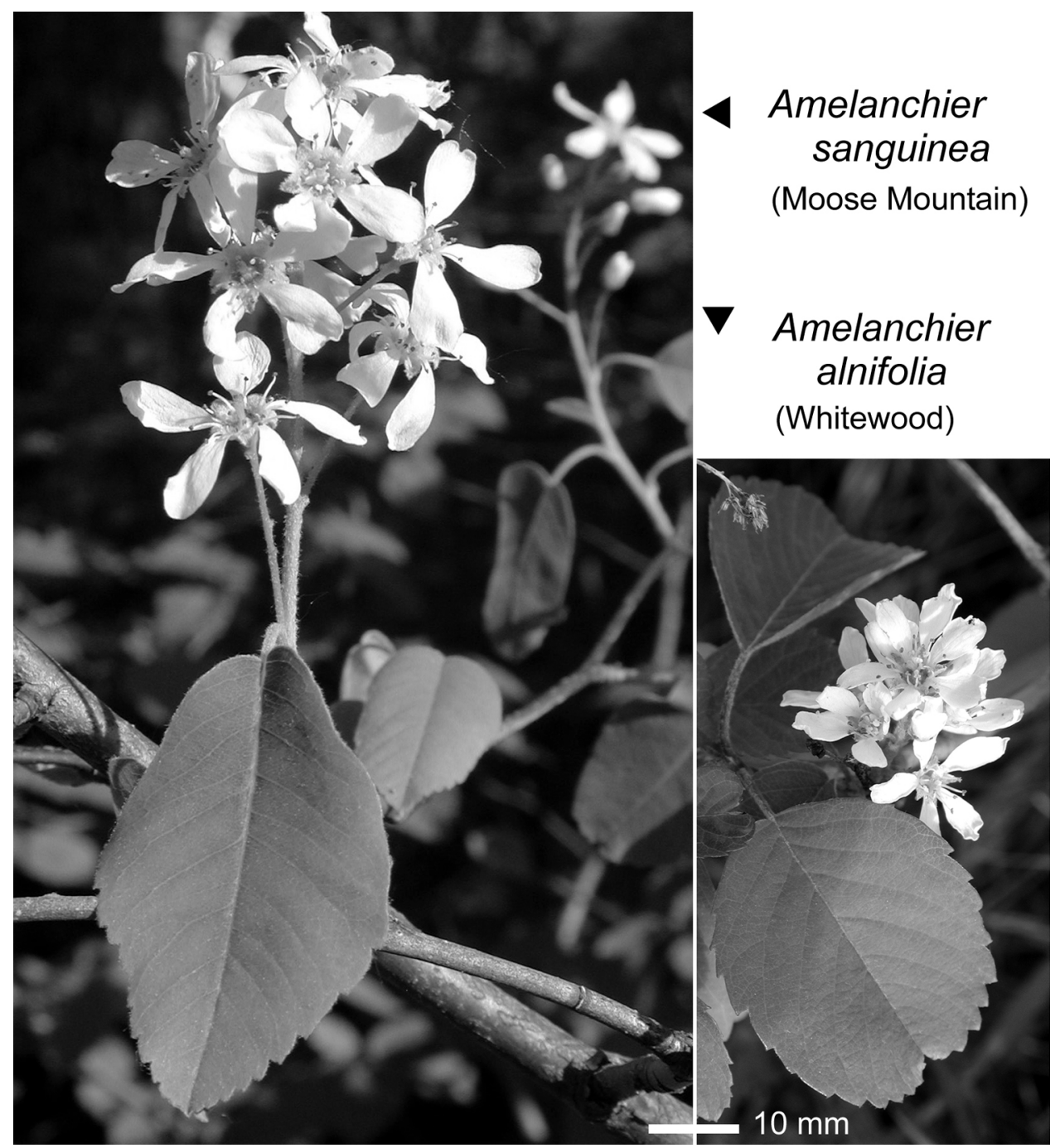

FIGURE 4. Amelanchier sanguinea from Moose Mountain, near White Bear Lake (left) with relatively long pedicels and open inflorescence and pointed oblong leaves. Amelanchier alnifolia (right) from relict prairie along the railway west of Whitewood with a dense infloresence, relatively short pedicels and a truncate and rounded leaf.

It appears that $A$. sanguinea is uncommon in the Moose Mountain upland whereas hybrids with $A$. alnifolia that have inflorescence features of A. alnifolia, and other characters in various combinations, are frequent. In many cases the difficulty in identifying Amelanchier material has been attributed to hybridization, introgression and agamospermy (e.g., Robinson 1982; Campbell and Wright 1996) but this aspect has yet to be investigated in the prairie region. There is much more variation in plants referred to A. alnifolia than was previously suspected. This variability appears to have a pattern to some extent associated with biogeographic boundaries. The correlation with biogeog- raphy may provide a useful basis for the utilization and protection of germplasm and it may also provide a means of determining groups and optimal characters in future taxonomic studies.

It is possible that differentiation of Amelanchier related to forested or unforested habitats in central North America has been going on for many thousands of years and that this phenomenon spread into southeastern Saskatchewan from the south following melting of the continental glacier about 10000 years ago. Plants corresponding to Amelanchier sanguinea may have been present in the Moose Mountain area with early postglacial poplar- or spruce (Picea) dominated 
TABLE 1. Significance of F-ratios from simple regression for seven characteristics of Amelanchier in the Whitewood area of southeastern Saskatchewan. A significant relationship is defined as below 0.05 and is shown with boldface.

\begin{tabular}{|c|c|c|c|c|c|c|c|}
\hline Character & (1) & (2) & (3) & (4) & (5) & (6) & (7) \\
\hline (1) pedicel length & - & & & & & & \\
\hline (2) leaf tip & 0.0679 & - & & & & & \\
\hline (3) leaf shape (1/w) & 0.1463 & 0.0000 & - & & & & \\
\hline (4) leaf pubescence & 0.3619 & 0.8416 & 0.7942 & - & & & \\
\hline (5) sepal length & 0.0009 & 0.6304 & 0.0675 & 0.9942 & - & & \\
\hline (6) height & 0.0000 & 0.3648 & 0.7270 & 0.0003 & 0.0000 & - & \\
\hline (7) ecodistrict & 0.0000 & 0.3938 & 0.2410 & 0.0675 & 0.0000 & 0.0000 & - \\
\hline
\end{tabular}

forests that were widespread for a short period about 10000 years ago, prior to replacement by persisting grassland (e.g., Ritchie 1976), which isolated the forested uplands. Alternatively these plants could have invaded after the Moose Mountain forest was isolated. Consumption of seeds by berry-eating birds would allow long-distance dispersal between forest patches. The recent discovery is not an indication of very recent arrival (although that is a possibility); rather it suggests that the classification and ecology of Amelanchier on the Canadian prairies is not well understood and requires much more study.

\section{Acknowledgments}

Useful reviews were provided by W. J. Cody and J. Cayouette. For extensive help in the field, we are indebted to B. Kostiuk. Staff of Moose Mountain Park provided useful information.

\section{Literature Cited}

Agriculture and Agri-Food Canada, Research Branch, Canadian Soil Information System. 1995. Terrestrial Ecozones, ecoregions and ecodistricts - Alberta, Saskatchewan and Manitoba. Map car019, scale 1/3.500,000.

Boivin, B. 1967. Flora of the prairie provinces. Part I. Provancheria 2, reprinted from Phytologia 15(6): 330-446.

Campbell, C. S., and W. A. Wright. 1996. Apomixis, hybridization, and taxonomic complexity in eastern North American Amelanchier (Rosaceae). Folia Geobotanica et Phytotaxonomica 31: 345-354.

Catling, P. M., and B. Kostiuk. 2006. Tallgrass prairie in the Whitewood area of Saskatchewan. Blue Jay 64: 72-83.

Catling, P. M., and E. Small. 2003. Poorly known economic plants of Canada 37. Saskatoon, Amelanchier alnifolia Canada's National Fruit? Canadian Botanical Association Bulletin 36(2): 20-26.

Cinq-Mars, L. 1971. Le genre Amélanchier au Québec. Le Naturaliste canadien 98: 329-346.

Fernald, M. L. 1950. Gray's manual of botany. American Book Company, New York. 1632 pages.
Gleason, H. A., and A. Cronquist. 1991. Manual of the vascular plants of the northeastern United States and adjacent Canada. $2^{\text {nd }}$ ed. New York Botanical Garden, Bronx. 993 pages.

Harms, V. L. 2003. Checklist of the vascular plants of Saskatchewan and provincially and nationally rare native plants of Saskatchewan. University of Saskatchewan Press, Saskatoon. 328 pages.

Jones, G. N. 1946. American species of Amelanchier. University of Illinois, Illinois Biological Monographs 20(2): 1126.

Looman, J. 1979. Budd's flora of the Canadian prairie provinces. Agriculture Canada Research Branch Publication 1662. 863 pages.

McGregor, R. L., and Great Plains Flora Association. 1977. Atlas of the flora of the Great Plains. Iowa State University Press, Ames. 600 pages.

McGregor, R. L., and Great Plains Flora Association. 1986. Flora of the Great Plains. University Press of Kansas. 1392 pages.

McKay, S. M. 1973. A biosystematic study of the genus Amelanchier in Ontario. M.Sc. thesis, University of Toronto. 241 pages + appendices.

McKay, S. M. 1975. Amelanchier alnifolia Nutt. var. compacta (Nielson) McKay. Ontario Field Biologist 29(2): 10.

McKay, S. M. 1976. Basionym for the new combination Amelanchier alnifolia Nutt. var. compacta (Nielson) McKay. Ontario Field Biologist 30(1): 55.

Nielsen, E. L. 1939. A taxonomic study of the genus Amelanchier in Minnesota. American Midland Naturalist 22: 160-205.

Ritchie, J. C. 1976. The late quaternary vegetational history of the western interior of Canada. Canadian Journal of Botany 54: 1793-1818

Robinson, W. A. 1982. Experimental taxonomy in the genus Amelanchier II: Do the taxa in the genus Amelanchier form an agamic complex? Rhodora 84(837): 85-100.

Stephenson, H. A. 1973. Woody plants of the North Central Plains. University of Kansas, Lawrence. 530 pages.

Received 26 September 2005

Accepted 6 February 2007 